\title{
Cyber Bullying Through Social Media Among Basic Stage Students at Directorate of Education of the University District/Capital Governorate
}

\author{
Iyad Jerias Alshawareb ${ }^{1} \&$ Mo'en Salman Alnasraween ${ }^{1}$ \\ ${ }^{1}$ Amman Arab University, Amman, Jordan \\ Correspondence: Iyad Jerias Alshawareb, Amman Arab University, Amman, Jordan.
}

Received: December 5, 2018

Accepted: January 29, 2019

Online Published: December 30, 2019

doi:10.5539/ies.v13n1p104

URL: https://doi.org/10.5539/ies.v13n1p104

\begin{abstract}
The aim of this study was to identify the level of cyberbullying through the means of social media among the students of the basic stage in the Directorate of Education of the University District, the sample of the study consisted of 388 students from the seventh and tenth grades. To achieve the objectives of the study, a questionnaire was developed for the cyberbullying, which consisted of 30 items in its final form, and its validity and reliability were verified, the results of the study showed that there was a moderate level of cyber bullying in the sample of the study. There were no differences between the statistical averages according to gender. However, there were differences of statistical significance attributed to the grade and in favor of the tenth grade.
\end{abstract}

Keywords: cyber bullying, social networking sites

\section{Introduction}

The era in which we live is the era of knowledge explosion and the digital revolution and rapid changes and successive in all areas, and social networks find a great success and popularity among the members of the society, and spread to link human relations between the countries of the world and its continents. The world has become a small village that one can travel through its continents and countries by controlling some buttons on the keyboard of the computer or mobile device (Trolley, Hanel, \& Shields, 2006).

In recent years, the World Wide Web has witnessed a remarkable development, its role is not only to communicate, but has expanded to become a major tool in the educational process. New and sophisticated web-based tools have emerged in a more interactive and participatory manner, which led to the entry of the internet at an advanced stage of the stages of development called social networking sites and has been able to provide all the advantages of attracting large numbers of users as the user becomes a product of the information and not consumer of it (Donegan, 2012).

Before the emergence of the term "social media sites" there was so-called Web 1.0 and Web 1.5 where most of the features of Web 1.0 that it includes static $(\mathrm{Html})$ pages, and rarely updated, web 1.5 is a dynamic web that quickly creates web pages through the contents of databases used in page management. Then came social networking sites that are not only dynamic web pages, but multimedia has been used more widely and comprehensively by providing images, videos, blogs and more (Swearer, Wang, Mang, Siebecker, \& Frerichs, 2012).

Social networking sites began to emerge in the late 1990s as Classmates.com (1995) used to connect colleagues, a series of social networks emerged between the years 1999-2001 but could not continue. It was the real birth of social networking as we know it today (2002) with the emergence of Friendster site, which was a great success at the time. In the second half of the same year, the Skyrock network appeared in France as a blogging platform. At the beginning of 2005, the American MySpace site appeared has exceeded the number of views of Google at the time, and is one of the first and largest social networks in the world and is in competition with Facebook, which began to spread parallel to MySpace, but it has attracted large numbers of users worldwide (Wang \& Nansel, 2009).

And bullying as a negative behavior repeated over time and take different forms and can be delivered through people directly or through technology, as its beginnings are still in school students, the evolution of this behavior is the result of industrial and technological development and the development of communication technologies, and the increase in the phenomenon of cyber bullying among adolescents who use the internet by $93 \%$ and $75 \%$ of adolescents use smart phones and their various applications, which increased the negative effects on all aspects of 
growth (Schneider, Donnell, Stueve, \& Couter, 2012).

Cyber bullying includes behaviors such as the contempt in online chat rooms, or intentionally harming another person by sending an offensive text or fabricated video; electronic space is a powerful means of bullying; making them bolder because it enables them to stay anonymous sometimes to the other party through the use of fictitious accounts with names and images is not real, as well as many of the discussions that are taking place are not supervised, it is therefore not difficult for victims to avoid those who have the potential to bully (Hinduja \& Pachin, 2008).

Therefore, the importance of this study to identify the level of cyber bullying through the means of social media among students in the basic stage, because this behavior of the consequences and effects of psychological bullying on them; can undermine the freedom of students in the use of electronic resources, may increase feelings of inferiority, and may lead to social problems and problems with school are associated if the bully is not confronted with an end to this negative behavior.

\subsection{Problem of the Study}

The problem of the study comes from the importance of social networking sites and their high prevalence, and the high demand for students on these sites, and despite the advantages of these sites, but these sites have produced many problems, including electronic bullying, students were exposed to problems during their use of these sites. This study was conducted to determine the prevalence of this phenomenon among the students of the basic stage in the directorate of education for university district.

\subsection{Study Questions}

This study attempted to answer the following questions:

1) What is the level of electronic bullying among the students of the basic stage inthe directorate of education for university district?

2) Are there statistically significant differences between the arithmetic mean of the level of cyber bullying in the primary stage students due to gender, grade and interaction between them?

\subsection{The importance of the study}

1) The theoretical importance of this study: is in addressing one of the important research topics in the field of cognitive psychology and educational psychology, and learning strategies, which is cyber bullying, this study also draws the attention of educators and parents to the need to pay attention to this subject.

2) The practical importance of this study is: to draw the attention of researchers and interested to the scale of electronic bullying, which has appropriate psychometric characteristics: to be used in similar studies.

\subsection{Definition of Study Terms}

1) Cyber bullying: Buffy and Dianne (2009) defined cyber bullying as: a state of harassment by a person who hovers remotely through cyberspace using electronic means of communication to create a psychological state of the victim, characterized by anxiety and threat.

And it is defined procedurally in this study to the overall degree obtained by the respondents by responding to the items of the scale of cyber bullying, which was developed for the purposes of this study.

2) Social Media Sites: Is a group of electronic networks spread globally through the Internet, and allows the participant to create a site of his own, ensuring that it can be linked to other sites and other members have the same interests and hobbies. It is intended in the present study: A set of web-based applications such as blogs, YouTube, Wiki, Facebook, Twitter, MySpace, and Google Plus, which enables students to use and discover the degree of bullying in it. This is measured by students' responses to the study tool.

\subsection{Limits of the Study}

The study is determined by the following limits:

1) Human boundaries: The study was applied to a sample of seventh and tenth grade students.

2) Time boundaries: The study was conducted during the second semester of the academic year (2017-2018).

3) Spatial boundaries: Directorate of Education of the university District.

\subsection{Determinants of the Study}

This study is limited to the tools used in it, and the methodology that has been followed. Therefore, the validity of the findings of the study is determined by the validity of the tools and their reliability, and the validity of the 
methodology followed in this study.

The generalization of the results of this study is determined by the appropriateness of the instruments used, and their degree of validity and reliability.

\section{Previous Studies}

The researchers reviewed some studies relating cyber bullying; some of these studies are the following:

Almakanin and Alhayari (2018) conducted a study in the city of Zarqa in Jordan aimed at identifying the levels of electronic bullying in a sample of students who are behavioral and emotional disturbed and the difference in levels of bullying, which is attributed to the gender and agevariables, to achieve the objectives of the study an electronic bullying scale and behavioral disturbance scale were used. The study sample consisted of 117 students from four schools in the director of education of Zarqa for the academic year 2015-2016.

The results of the study showed that the level of electronic bullying in the study sample was high. The results of the study also showed differences in the levels of electronic bullying among students according to the gender variable was high among male students compared to females and the age group greater than 14 years.

Al-Othman and Ali (2014) conducted a study aimed to identify the methods of electronic bullying in general education students, in addition to the types of electronic bullying through text messages, telephone, E-mail. The study sample was 420 male and female students from the Cairo and Qalqilya schools. The age of study sample members was (11-18) years old. The study concluded that there was a difference in the technological superiority among the students in the academic stages. The difference was in the distance of telephone call among secondary and middle school students.

In a study by Schneider et al. (2012) aimed at revealing the relationship between electronic and traditional bullying in school, and its impact on the emotional aspects of the study sample which composed of 2000 students of the Metro West schools in Boston, Massachusetts. The results of the study indicated the prevalence of electronic bullying quickly among adolescents, the results of the study indicated the prevalence of electronic bullying among teenagers. The relationship between electronic and traditional bullying was a positive one. Electronic bullying is associated with emotional effects rather than traditional bullying, whereas traditional bullying is associated with physical effects compared with electronic bullying.

In a study conducted by Kowalskia and Fedina (2011), the aim was to examine the differences between traditional bullying and bullying through computers and cell phones for children with special needs and those with hyperactivity and its association with the psychological and social health of the study sample. The sample of the study consisted of 42 children, the results of the study indicated that students are more prone to electronic bullying than traditional bullying.

Kowalski and Limber (2007) conducted a study aimed at identifying the prevalence of electronic bullying among middle school students, especially adolescent students, and studying the phenomenon of electronic bullying through e-mail and messages in chat rooms in websites, or through digital messages or images sent to mobile phones, the sample consisted of 3767 students in grades of sixth, seventh and eighth in six middle schools in the south-east and northwest of the United States of America, the results of the study showed that $11 \%$ of the students were bullying electronically, and $7 \%$ were victims of bullying and $4 \%$ practiced electronic bullying on another person. The results of the study showed that the most common method of electronic bullying is the use of E-mail, chat rooms and e-mail, as half of the victims of electronic bullying indicated they did not know the identity of the bully.

Jaradat (2016) conducted a study on the differences in bullying and victimization among optimistic and non-optimistic adolescents, the study sample consisted of 976 students from the seventh, eighth, ninth and tenth grades of the schools of Irbid Governorate, the results of the study showed statistically significant differences in favor of non-optimistic students in the victim of electronic extinction.

\section{Method and Procedures}

Methodology: This study used descriptive analytical method, being the most appropriate for the nature of the study.

\subsection{Population of the Study}

The study population is composed of all public schools in the Directorate of Education of the University District (For the seventh and tenth basic grades) during the second semester of the academic year (2017-2018) and its number 9 male schools and 14 female schools. The number of students in the study population reached 4958 students with 2022 students in the seventh grade and 2936 students in the tenth grade, according to the statistics of 
the Department of Planning and Formations in the Directorate for the year (2017-2018) first semester.

\subsection{The Study Sample}

The study sample consisted of 388 male and female students from the 7th and 10th grades in the directorate of education of the university district who were selected using the random manner.

\subsection{Study Tool}

\subsubsection{Cyber Bullying Scale}

In order to achieve the objectives of this study, the scale of electronic bullying, which is in its initial form of 33 paragraphs was developed by Buffy and Dianne (2009), as well as the Kowalskia and Fedina (2011) scale, were used.

\subsubsection{Validity and Reliability of the Scale}

The scale was presented to ten arbitrators with a specialization in education and psychology at the Jordanian universities, where they were asked to express opinions and make observations on the scale, where two items were deleted based on the suggestions of the arbitrators because of they are not suitable for the age stage, thus, the scale is in its final form consisted of (30) items.

In order to verify the reliability of the scale, it was applied to a sample of 40 students from outside the study sample,two weeks later, the application was re-implemented the correlation coefficient between the two applications was calculated at 0.83 , which is suitable for the current study. The internal consistency of the Kronbach Alpha was also calculated for the total score (0.90).

\subsubsection{Correction of Study Tool}

The five-step gradient was used in the study instrument as follows: Always (5) degrees, often (4) degrees, sometimes (3) degrees, rarely (2) degrees, and never (1) degree.

The levels of cyber bullying were judged by the following equation:

(Highest value in gradient - lowest value) $/ 3$

$(5-1) / 3=1.33$

The categories were thus formed as follows:

From (1-2.33) low

From (2.34-3.67) average

From (3.68-5) high

\section{Result}

Results related to the first question: What is the level of cyber bullying among the students of the basic stage in the Directorate of Education of the University district?

To answer this question, arithmetical averages and standard deviations were extracted, and Table 1 illustrates this. 
Table 1. The arithmetical averages, standard deviations, level and rank of the cyber bullying scale arranged in descending order

\begin{tabular}{|c|c|c|c|c|c|}
\hline $\mathrm{N}$ & Item & Mean & $\begin{array}{l}\text { Standard } \\
\text { deviation }\end{array}$ & Level & Rank \\
\hline 18 & One of my friends used the photos I posted on my account without taking my consent. & 3.89 & 1.02 & High & 1 \\
\hline 25 & One of my friends at school has already made a block for me. & 3.86 & 0.92 & High & 2 \\
\hline 19 & $\begin{array}{l}\text { One of my friends tried to embarrass me at school by using information I had posted on } \\
\text { my account. }\end{array}$ & 3.81 & 1.02 & High & 3 \\
\hline 1 & I had already received a morally inappropriate message from one of my online friends. & 3.80 & 0.83 & High & 4 \\
\hline 13 & One of my friends made a tag for me on an inappropriate publication. & 3.80 & 0.86 & High & 5 \\
\hline 20 & $\begin{array}{l}\text { One of my friends tried to embarrass me at school using photos I had posted on my } \\
\text { account. }\end{array}$ & 3.79 & 1.04 & High & 6 \\
\hline 16 & One of my friends posted my photo on a social networking site without my consent. & 3.73 & 0.90 & High & 7 \\
\hline 3 & $\begin{array}{l}\text { Someone who is not my friends commented morally inappropriate on one of my } \\
\text { publications. }\end{array}$ & 3.72 & 1.01 & High & 8 \\
\hline 30 & $\begin{array}{l}\text { Someone has already tried to spy on personal electronic information such as phone } \\
\text { number, etc. }\end{array}$ & 3.71 & 0.92 & High & 9 \\
\hline 5 & I received a morally inappropriate message from someone I do not know. & 3.70 & 0.86 & High & 10 \\
\hline 7 & $\begin{array}{l}\text { Someone who is not one of my electronic friends insulted me on a social networking } \\
\text { site. }\end{array}$ & 3.70 & 0.86 & High & 10 \\
\hline 28 & My account was already compromised. & 3.70 & 0.80 & High & 10 \\
\hline 4 & I received a morally inappropriate message from one of my friends. & 3.69 & 0.86 & High & 13 \\
\hline 2 & $\begin{array}{l}\text { one of my electronic friends commented morally inappropriate on one of my } \\
\text { publications. }\end{array}$ & 3.68 & 0.83 & High & 14 \\
\hline 27 & Someone has already made a report for your personal page. & 3.67 & 0.86 & Medium & 15 \\
\hline 9 & One of my friends added me to a chat room without my desire. & 3.60 & 0.82 & Medium & 16 \\
\hline 17 & $\begin{array}{l}\text { One of my friends posted a video about me on a social networking site without my } \\
\text { consent. }\end{array}$ & 3.60 & 0.85 & Medium & 16 \\
\hline 21 & One of my relatives tried to threaten me with information I had posted on my account. & 3.60 & 1.07 & Medium & 16 \\
\hline 29 & One of my email friends already sent me a message containing virus. & 3.60 & 0.82 & Medium & 16 \\
\hline 26 & One of my relatives has already blocked me. & 3.56 & 0.90 & Medium & 20 \\
\hline 24 & I have already been kicked out of a chat room for no reason or explanation. & 3.37 & 0.82 & Medium & 21 \\
\hline 6 & One of my electronic friends insulted me on a social networking site. & 3.33 & 0.90 & Medium & 22 \\
\hline 8 & One of my friends added me to a group without my desire. & 3.31 & 0.80 & Medium & 23 \\
\hline 10 & One of my friends posted inappropriate images on my own page to embarrass me. & 3.22 & 0.92 & Medium & 24 \\
\hline 11 & One of my friends posted an inappropriate video on my own page to embarrass me. & 3.22 & 0.88 & Medium & 24 \\
\hline 12 & One of my friends did a share on an inappropriate publication. & 3.21 & 0.89 & Medium & 26 \\
\hline 14 & I had already received a threatening message from one of my friends. & 3.18 & 0.91 & Medium & 27 \\
\hline 15 & I had already received a threatening letter from someone I did not know. & 3.16 & 0.94 & Medium & 28 \\
\hline 22 & One of my relatives tried to threaten me with photos I had posted on my account. & 2.85 & 1.07 & Medium & 29 \\
\hline 23 & I have already been kicked out of a group without explaining reasons & 2.76 & 1.07 & Medium & 30 \\
\hline \multicolumn{2}{|r|}{ Total } & 3.07 & 0.95 & \multicolumn{2}{|c|}{ Medium } \\
\hline
\end{tabular}

It is noted from Table 1 that the arithmetic mean of the electronic extensibility scale as a whole reached 3.07 and by standard deviation (0.95) at an average level, the averages for this scale were between the high and the middle level, ranging between 2.33 and 3.42, and the highest mean for paragraph (4), which stated that "one of my friends used the images I published on my account without taking my consent." with a value of 3.89, with a standard deviation of 1.02 and at a high level. The lowest mean of the paragraph (23), which stated that "I have already been kicked out of a group without explaining reasons.", With an arithmetic mean of 92.76 and standard deviation of 1.07 and at an average level, this result can be explained by the fact that this age group of students tends to imitate each other and use social networking sites without regard to ethical standards and without any guidance from home or school. The school curricula lack any reference to the dangers of creating electronic accounts on social networking websites, the results of this study were agreed with the study (Schneider et al., 2012), which aimed to reveal the relationship between electronic and traditional bullying in school, and its impact on the emotional aspects in the sample of the study consisting of 2000 students of schools Metro West in Boston, Massachusetts, 
where the results of the study indicate the prevalence of electronic bullying quickly among adolescents.

Results relating the second question: Are there statistically significant differences between the arithmetic mean of the level of cyber bullying in the primary stage students due to gender, grade and interaction between them?

To answer this question, Two-Way analysis of variance of the grade and gender variables was obtained on the averages of the scale of cyber bullying, as shown in Table 2.

Table 2. Results of Two-Way analysis of variance to test the significance of the differences between the arithmetic mean by gender, grade, and interaction between the two variables on the cyber bullying scale

\begin{tabular}{cccccc}
\hline Source of variance & Mean of squares & Df & Sum of squares & F value & Sig \\
\hline Gender & 0.295 & 1 & 0.295 & 2.525 & 0.119 \\
Class & 1.180 & 1 & 1.180 & 10.067 & $* 0.008$ \\
Class*Gender & 0.012 & 1 & 0.012 & 0.092 & 0.863 \\
ERROR & 47.522 & 354 & 0.134 & & \\
Total & 4010.129 & 358 & & & \\
\hline
\end{tabular}

The results of Table 2 indicate that there is no statistically significant effect of gender or gender interaction on the average responses of students on the scale of cyber bullying where the value level of (F) was greater than 0.05 in each case, the results of the table indicate that there is a statistically significant effect on the variable of grade. To find out the direction of these differences between the averages for the grade variable, the students' arithmetical averages were obtained on the scale of the electronic computation by the grade variable.

Table 3. Modified means and standard errors of students' grades on the cyber bullying scale according to class

\begin{tabular}{ccc}
\hline Class & Mean & Standard error \\
\hline $7^{\text {th }}$ grade & 3.024 & 0.876 \\
$10^{\text {th }}$ grade & 3.180 & 0.789 \\
\hline
\end{tabular}

The results of Table 3 indicate the differences between the arithmetic mean coefficients on the cyber bullying scale in favor of the $10^{\text {th }}$ grade, where the mean reached 3.180, while for the 7th grade reached 3.024, this result is attributed to the fact that by increasing the grade, the student's interest in social media increases, thus increasing the student's chances of cyber bullying. The results of this question are relatively consistent with the results of the Kowalski and Limber's (2007) study, which indicated the high rates of cyber bullying among adolescents, it also agreed with the study of Makanin and Hayari (2018), which indicated that the levels of cyber bullying increase with age.

\section{Conclusion}

Through many studies, abuse through school bullying and electronic bullying is a global problem spread across different countries and societies and has many negative and complex psychological, emotional, social or educational implications for the health of both the bullying and the victim. Compounding the seriousness of this problem is the high incidence of bullying, bullying and multiple forms during the last few years. Children who are exposed to bullying in school may suffer from several negative effects, including their effects on their cognitive abilities. These include: anxiety, tendency to loneliness, over-submission, growing sense of injustice, fear and loss of safety, Excessive activity, dropout, frequent absence, poor concentration, low levels of academic achievement. It is likely that there are intersections between traditional and electronic bullying in these effects, as children exposed to electronic bullying suffer from the same negative effects earlier, and the risk of these effects may increase with electronic bullying; it may occur without being known or seen by teachers and parents.

Electronic bullying is an indirect form of traditional school bullying, where the bully does not harass the victim by interacting face-to-face with him, but bullying him through the computer screen or mobile phone, like school bullying, cyber bullying is public, and is seen by some acquaintances, peers and strangers. For these reasons, school bullying is associated with online bullying.

Electronic bullying differs from traditional bullying face-to-face, since it is difficult to escape. Its electronic nature makes it happen without attracting the attention of teachers or parents. If information is sent or a post is posted on the web, it may be difficult for the victim to prevent it or deletes it from all the sites where it appears. Mason 
comment on the nature of cyber bullying that "The individuals can be harassed even when they are not in or around school". Unlike traditional bullying, the house is no longer a haven to stay away from the bully.

One of the unique features of electronic bullying is the ability of the bully to be unknown, and to bully with a large number of peers, with minimal effort, at any time and place during the day, and through electronic bullying it is possible for a bully to reach an online audience larger than it is present in the school domain.

\section{Recommendations}

In the light of the results of the study, the researchers recommended the following:

- Conducting further studies on cyber bullying.

- Educating parents about the dangers of cyber bullying.

- Holding workshops for students on the use of social media

\section{References}

Al-Othman, K., \& Ali, A. (2014). Cyber bullying among students in general education. Psychological Study, 24(2), 185-212.

Buffy, F., \& Dianne, O. (2009). Cyberbullying: A literature Review. Paper presented at the Annual Meeting of the Louisiana Education Research Association Lafayette.

Donegan, R. (2012). Bullying and cyberbullying: History, statistics, law, prevention and analysis. The Elon Journal of Undergraduate Research in Communications, 3(1), 33-42.

Hinduja, S., \& Patchin, J. (2008). Cyberbullying an exploratory analysis of factors related to offending and victimization. Deviant Behavior, 29(2), 129-156. https://doi.org/10.1080/01639620701457816

Jaradat, A. (2016). Differences in bullying and victimization among optimistic and not optimistic adolescents. Educational Science Studies, 43(1).

Kowalski, R. M., \& Fedina, C. (2011). Cyber bullying in ADHD and Asperger Syndrome populations. Research in Autism Spectrum Disorders, 5, 1201-1208. https://doi.org/10.1016/j.rasd.2011.01.007

Kowalski, R. M., \& Limber, S. P. (2007). Electronic bullying among middle school students. Journal of adolescent health, 41(6), S22-S30. https://doi.org/10.1016/j.jadohealth.2007.08.017

Makanin, H., Younis, N., \& Hayari, G. (2017). Cyber bullying in a sample of behavioral and emotional disturbed students in Zarqa. Journal of Educational and Psychological Studies, Sultan Qaboos University, 12(1), 179-197. https://doi.org/10.24200/jeps.vol12iss1pp179-197

Schneider, S., Donnel, L., Stueve, A., \& Couter, R. (2012). Cyberbullying, school bullying, and psychological distress: A very lonal census of high school students. American Journal Public Health, 102(1), 171-177. https://doi.org/10.2105/AJPH.2011.300308

Swearer, S. M., Wang, C., Maag, J. W., Siebecker, A. B., \& Frerichs, L. J. (2012). Understanding the bullying dynamic among students in special and general education. Journal of School Psychology, 50(4), 503-520. https://doi.org/10.1016/j.jsp.2012.04.001

Trolley, B., Hanel, C., \& Shields, L. (2006). Demystifying \& deescalating cyber bullying in the schools: A resource guide for counselors, educators and parents. Booklocker.com, Inc.

Wang, R., \& Nansel, T. (2009). School bullying among adolescents in the United States: Physical, verbal, relational, and cyber. Journal of Adolescent Health, 45(4), 368-375. https://doi.org/10.1016/j.jadohealth.2009.03.021

\section{Copyrights}

Copyright for this article is retained by the author(s), with first publication rights granted to the journal.

This is an open-access article distributed under the terms and conditions of the Creative Commons Attribution license (http://creativecommons.org/licenses/by/4.0/). 